\title{
SAPAAN KEKERABATAN BAHASA KERINCI DI KECAMATAN GUNUNG RAYA KABUPATEN KERINCI
}

\author{
Viki Diyanti \\ Universitas Gadjah Mada, Indonesia \\ Vikidiyanti95@gmail.com \\ Subiyantoro \\ Universitas Gadjah Mada, Indonesia \\ Subiyantoro_1@ugm.ac.id
}

Accepted: 2021-06-15, Approved: 2021-07-01 , Published: 2021-07-05

\begin{abstract}
This article aims to analyze the types of kinship greeting words in Kerinci language and social factors that influence the types of kinship greeting words in Kerinci language in Gunung Raya sub-district, Kerinci district. This research uses a qualitative approach with descriptive methods. The research data is the kinship greeting words in Kerinci language in Gunung Raya sub-district, Kerinci district. The research data comes from informants as native speakers of Kerinci language who live in Gunung Raya subdistrict.The result of this study is the community kinship system of Gunung Raya subdistrict based on matrilineal lineage, someone will follow the lineage of mother. The male becomes a kindred based on the marriage line. The kinship greeting words in Kerinci language in Gunung Raya sub-district based on the lineage consist of 25 greeting words, while the kinship greeting words in the Kerinci language in Gunung Raya sub-district based on the marriage line consist of 29 greeting words. Social factors that influence the form of kinship greeting words in Kerinci language in Gunung Raya sub-district are social distance, age, gender, social status, physical characteristics, and language contact.
\end{abstract}

Keyword: greeting words; Kerinci language; kinship; Gunung Raya sub-district

\section{PENDAHULUAN}

Manusia merupakan makhluk yang tidak lepas dari interaksi satu sama lain. Dalam berinteraksi, adat istiadat, etika, ilmu pengetahuan, dan budaya saling berkaitan sehingga tidak mudah untuk menyesuaikan perbedaan yang terjadi dalam berinteraksi (Hildayani, 2019). Untuk mewujudkan sebuah interaksi sosial, manusia harus mampu berkomunikasi dengan baik. Ada tiga komponen yang harus ada dalam setiap proses komunikasi, yakni pihak yang berkomunikasi (penutur dan mitra tutur), informasi yang dikomunikasikan, dan alat yang digunakan dalam berkomunikasi (Chaer dan Agustina,
2010). Bahasa menjadi sarana yang menunjang penutur dan mitra tutur dalam berkomunikasi. Bahasa menjadi tanda pengenal seorang penutur.

Bahasa daerah menjadi bagian dari aset penting bangsa Indonesia. Negara Indonesia memiliki beragam bahasa daerah yang tersebar dari Sabang sampai dengan Merauke. Setiap bahasa daerah memiliki keunikan dan kekhasan masing-masing. Bahasa Kerinci merupakan salah satu bahasa daerah yang digunakan oleh masyarakat asli Kabupaten Kerinci. Bahasa Kerinci memiliki dialek yang berbeda-beda meskipun daerah-daerah di Kerinci hanya dibatasi oleh sungai. Penutur 
bahasa Kerinci antar dialek bahkan tidak memahami bahasa mitra tutur.

Keberadaan bahasa Kerinci di tengah masyarakat multilingual dan multietnis menjadi tantangan tersendiri bagi penutur bahasa Kerinci. Mereka sudah mulai menguasai banyak bahasa sehingga hal tersebut memberikan pengaruh pada bahasa Kerinci. Kehadiran bahasa-bahasa lain mulai mengikis bahasa Kerinci secara perlahan. Pentingnya penelitian bahasa Kerinci dilakukan agar bahasa Kerinci tetap terjaga kelestariannya dari satu generasi ke generasi berikutnya dan terhindar dari kepunahan bahasa.

Bahasa Kerinci termasuk rumpun Melayu yang menggambarkan kombinasi antara dialek tradisional Melayu dan karakter lainnya yang sangat berbeda dengan variasi bahasa Melayu lainnya (Rina \& Rahman, 2016). Pada hakikatnya bahasa Kerinci mengenal variasi bahasa yang berupa variasi-variasi lokal yang pada prinsipnya dapat disebut dialek. Bahasa Kerinci digolongkan ke dalam tiga kelompok dialek besar, yakni dialek kerinci Hulu, dialek Kerinci Tengah, dan dialek Kerinci Hilir (Anwar dalam Maiza, 2018). Penelitian ini difokuskan pada bahasa Kerinci dialek Kerinci Hilir di Kecamatan Gunung Raya, Kabupaten Kerinci.

Sebagai bahasa ibu, bahasa Kerinci digunakan sebagai alat untuk bertegur sapa antar penutur. Saat penutur hendak menyapa seseorang menggunakan bahasa Kerinci, penutur bisa saja menggunakan kata sapaan yang berbeda-beda. Salah satu hal yang mempengaruhinya adalah hubungan kekerabatan. Ego harus memperhatikan hubungannya dengan orang yang hendak disapa dan memilih kata sapaan yang tepat. Misalnya, kata sapaan 'ayah' untuk menyapa ayah kandung dan kata sapaan 'om' untuk menyapa kakak atau adik dari ibu kandung.

Saat ini, kata sapaan kekerabatan dalam bahasa Kerinci di kecamatan Gunung Raya kabupaten Kerinci semakin bervariasi. Hal tersebut disebabkan karena bahasa Kerinci terus mengalami perkembangan. Ada banyak faktor yang dapat dikaitkan dengan kondisi terkini bahasa Kerinci di kecamatan Gunung Raya. Dengan adanya penelitian terkait kata sapaan kekerabatan dalam bahasa Kerinci di kecamatan Gunung Raya maka penelitian tersebut dapat dijadikan sumber inventaris bahasa daerah. Di samping itu, penelitian kata sapaan bahasa Kerinci yang dilakukan berupaya untuk mengetahui leksikonleksikon asli bahasa Kerinci dan leksikon-leksikon baru dalam bahasa Kerinci.

Yang dalam Aditama dkk (2020) menyatakan ada beberapa alasan seseorang menggunakan kata sapaan, di antaranya yaitu: pertama, untuk menarik perhatian orang lain dalam berkomunikasi, agar terlihat jelas status lawan bicara atau hubungan penutur dan petutur. Kedua, menunjukkan kesopanan. Ketiga, agar diketahuinya jenis kelamin, identitas, usia, status, dan hubungan sosial. Martin dalam Dama (2018) menyatakan ada empat faktor fundamental dalam pemilihan kata yang tepat untuk menunjukkan kesopanan, yakni jenis sapaan yang digunakan untuk menyapa orang lain, mempertimbangkan keberadaan orang yang berasal dari komunitas berbeda, posisi sosial, usia, dan jenis kelamin.

Sapaan digunakan untuk menyapa orang yang berbeda-beda karena bergantung pada hubungan dengan orang tersebut di dalam komunikasi (Sari dalam Temaja, 2018). Sejalan dengan pendapat tersebut, Wardhaugh \& Fuller (2015) 
menyatakan bahwa saat menyapa orang lain, pilihan kata sapaan disesuaikan dengan usia, hubungan dengan orang yang disapa, dan konteks komunikasi yang berlangsung. Dalam realisasinya, secara lingual bentuk sapaan dapat berupa morfem, kata, ataupun frasa (Kridalaksana dalam Temaja, 2018). Kridalaksana dalam Misnawati (2017) mengatakan bahwa ada 9 jenis kata sapaan dalam bahasa Indonesia, yaitu: (1) kata ganti, seperti aku, kamu, engkau ia, kami, mereka, dan sebagainya; (2) nama diri, seperti nama orang yang dipakai untuk semua pelaku tuturan; (3) istilah kekerabatan, seperti bapak, ibu, saudara, teman, paman, adik, dan sebagainya; (4) gelar dan pangkat, seperti dokter, guru, jendral, dosen, dan sebagainya; (5) bentuk pe + $\mathrm{V}$ (verbal) atau kata pelaku, seperti pendengar, pembaca, penumpang, penonton, dan sebagainya; (6) bentuk $\mathrm{N}$ (nominal) $+\mathrm{ku}$, seperti Tuhanku, kekasihku, bangsaku, dan sebagainya; (7) kata-kata deiksis, seperti ini, itu, situ, dan sebagainya; (8) nominal (kata benda yang dibendakan), seperti tuan, nyonya, yang mulia, dan sebagainya; dan (9) ciri zero atau nol.

Bila dihubungkan dengan kata sapaan istilah kekerabatan, Huki dalam Mawara (2015) berpendapat bahwa istilah kekerabatan digunakan untuk menunjukkan identitas para kerabat sehubungan dengan penggolongan kedudukan mereka dalam hubungan kekerabatan masing-masing dengan ego. Menurut Masruddin (2015) ada dua istilah penting yang dikenal dalam ilmu antropologi, yakni term of reference (istilah kekerabatan) dan term of address (kata sapaan). Istilah pertama mengacu pada kata-kata yang menunjuk atau mengacu pada hubungan kekeluargaan, misalnya kakak, adik, bapak, bibi, ipar, dan lainnya. Istilah kedua mengacu kepada bagaimana kita menyapa atau memanggil orang-orang sekeluarga tersebut, misalnya 'bi' adalah sapaan untuk bibi.

Tiga sistem kekerabatan yang mendasar terdiri atas bilateral, patrilineal, dan matrilineal. Dalam sistem bilateral, orang-orang yang berkerabat adalah mereka yang dilahirkan dari ayah dan ibu yang sama, kerabat-kerabat ayah dan ibu, anak-anak dari saudara ayah dan saudara-saudara ibu, dan semua leluhur dan keturunannya. Dalam sistem patrilineal, orang-orang yang berkerabat ditelusuri menurut garis laki-laki. Dalam sistem matrilineal, keturunan ditelusuri berdasarkan atas garis ibu atau menurut garis perempuan (Suparlan dalam Mawara, 2015).

Kata sapaan mencakup salah satu aspek bahasa yang dalam penggunaannya selalu mementingkan faktor sosial budaya dan situasi penggunaanya (Dama, 2018). Faktorfaktor yang mempengaruhi penggunaan kata sapaan, yakni yakni (1) kontak, (2) jarak sosial, (3) in-groupness, dan (4) identitas tersapa. Kontak antara pelaku pembicaraan dapat berlangsung sebentar dan bersifat santai atau dapat juga berlangsung lebih lama dan bersifat serius. Jarak sosial antara penyapa dan tersapa dapat bersifat jauh, sedang, atau akrab. Jika jarak sosial antara penyapa dan tersapa dirasa dekat, penyapa perlu memperhatikan identitas tersapa. Faktor in-groupness menyangkut masalah apakah penyapa dan tersapa seusia, apakah mereka teman sekelas atau teman satu sekolah, apakah mereka satu profesi, apakah mereka berasal dari daerah yang sama, apakah mereka masih ada hubungan keluarga, apakah mereka dari suku yang sama, atau apakah mereka dari organisasi yang sama. Di samping itu, penyapa masih harus memperhatikan faktor identitas pelaku seperti jenis 
kelamin, usia, status, dan pangkat/kedudukan tersapa (Suhardi, 2017).

Penelitian tentang sapaan kekerabatan sudah banyak dilakukan oleh para peneliti. Penelitian-penelitian tersebut berfokus pada bahasa-bahasa daerah. Penelitian Miftahul Jannah, Rajab Bahry, dan Saifuddin Mahmud (2019) tentang Penggunaan Sapaan Kekerabatan dalam Tuturan Masyarakat Kabupaten Batu Bara Provinsi Sumatra Utara berfokus pada bentuk sapaan hubungan kekerabatan dan penggunaan sapaan hubungan kekerabatan dalam tuturan masyarakat di kabupaten Batu Bara Provinsi Sumatra Utara. Hasil penelitian tersebut yakni penggunaan sapaan kekerabatan dalam tuturan masyarakat Kabupaten Batu Bara, Provinsi Sumatera Utara berdasarkan pada urutan kelahiran dan generasi. Dalam tuturan masyarakat Kabupaten Batu Bara dikenal sepuluh macam sapaan berdasarkan urutan kelahiran. Sapaan-sapaan dalam tuturan masyarakat Kabupaten Batu Bara dipengaruhi oleh hubungan kekerabatan karena keturunan, perkawinan, dan hubungan peran.

\begin{tabular}{lll}
\multicolumn{2}{c}{ Penelitian Rini Habsy (2018) } \\
tentang Penggunaan Sapaan
\end{tabular}

Kekerabatan bahasa Makean dialek Samsuma di desa Samsuma kecamatan Malifut, hasil penelitian yang ditemukan yakni kata sapaan dalam keluarga inti terdiri atas lima jenis sapaan. Penggunaan kata sapaan pada bahasa Makean dialek Samsuma ini berbeda dengan bahasa Jawa dan sebagainya sebab pada penggunaannya tidak digunakan untuk orang yang disapa melainkan untuk membuat atau menjawab pertanyaan tentang siapa (anak siapa, adik siapa, kakak siapa). I Nyoman Suwija (2018) melakukan penelitian tentang Sistem Sapaan Bahasa Bali menurut Hubungan
Kekerabatan. Kata sapaan dalam bahasa Bali cukup banyak dan bervariasi. Hal itu disebabkan oleh bentuk hubungan kekerabatan yang meliputi faktor: usia partisipan, kedudukan dalam keluarga, jenis kelamin, dan hubungan keluarga langsung. Penggunaan bentuk-bentuk sapaan dalam bahasa Bali dapat mengalami perubahan bentuk atau varian tergantung situasi pembicaraan dan status sosial para partisipan.

Penelitian tentang kata sapaan kekerabatan bahasa Kerinci di kecamatan Gunung Raya berbeda dari penelitian-penelitian sebelumnya. Penelitian ini tidak hanya membahas bentuk-bentuk kata sapaan kekerabatan bahasa Kerinci, namun juga membahas faktor-faktor sosial yang mempengaruhi bervariasinya kata sapaan kekerabatan bahasa Kerinci. Di samping itu, peneliti juga mencantumkan diagram pohon untuk menjelaskan kedudukan ego dalam silsilah keluarga. Peneliti memilih kecamatan Gunung Raya sebagai objek penelitian karena belum ada penelitian sosiolinguistik yang dilakukan di wilayah tersebut. Adapun fokus penelitian ini yakni (1) jenis-jenis kata sapaan kekerabatan bahasa Kerinci di kecamatan Gunung Raya, kabupaten Kerinci dan (2) faktor-faktor sosial yang mempengaruhi bentuk sapaan kekerabatan bahasa Kerinci di kecamatan Gunung Raya, kabupaten Kerinci. Tujuan penelitian ini yakni (1) mendeskripsikan jenis-jenis kata sapaan kekerabatan bahasa Kerinci di kecamatan Gunung Raya, kabupaten Kerinci dan (2) mendeskripsikan faktorfaktor sosial yang mempengaruhi bentuk sapaan kekerabatan bahasa Kerinci di kecamatan Gunung Raya, kabupaten Kerinci.

\section{METODE}

Penelitian ini menggunakan pendekatan kualitatif dengan metode 
deskriptif. Objek penelitian yang dipilih yakni bahasa Kerinci dialek Gunung Raya. Data penelitian terdiri atas data primer, yakni kata sapaan kekerabatan dalam bahasa Kerinci di Kecamatan Gunung Raya. Sumber data penelitian berasal dari informan selaku masyarakat yang tinggal di wilayah kecamatan Gunung Raya. Informan yang terpilih merupakan penutur asli bahasa Kerinci.

Pengumpulan data menggunakan teknik observasi, teknik wawancara, teknik rekam, dan teknik catat. Peneliti melakukan observasi lapangan di wilayah kecamatan Gunung Raya. Peneliti ikut terlibat langsung dalam tuturan informan yang terpilih. Di samping itu, data dikumpulkan dengan mewawancarai informan terpilih. Jenis wawancara yang dilakukan yakni wawancara pembicaraan formal. Wawancara tersebut biasanya dilakukan pada latar alamiah. Hubungan antara pewawancara dengan yang diwawancarai dalam suasana biasa dan wajar (Barlian, 2016). Peneliti merekam dan mencatat data yang didapat selama proses wawancara

Berikut ini adalah sebuah diagram pohon sapaan kekerabatan berdasarkan garis keturunan:

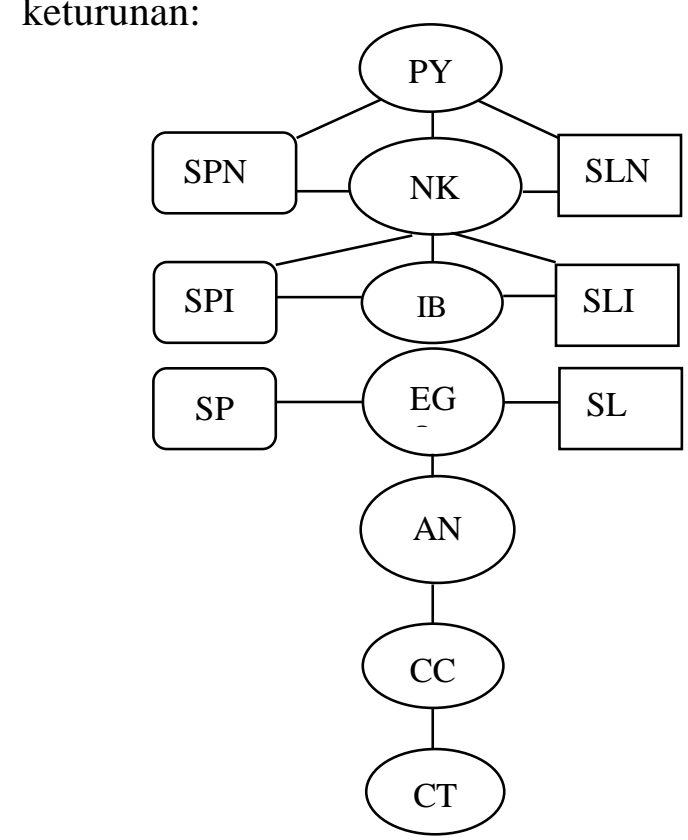

berlangsung. Data yang telah dikumpulkan kemudian dianalisis dengan langkah-langkah berikut: (1) peneliti mengklasifikasikan kata sapaan kekerabatan bahasa Kerinci berdasarkan kategorinya, (2) masing-masing kata sapaan kekerabatan bahasa Kerinci diterjemahkan ke bahasa Indonesia, kemudian (3) mendeskripsikan masingmasing kata sapaan kekerabatan bahasa Kerinci.

\section{HASIL DAN PEMBAHASAN}

Berdasarkan adat yang berlaku di kecamatan Gunung Raya, Kabupaten Kerinci, masyarakat menganut garis keturunan dari pihak perempuan (matrilineal). Artinya, pihak perempuan menjadi kerabat berdasarkan garis keturunan dan pihak laki-laki menjadi kerabat berdasarkan garis perkawinan. Kata sapaan kekerabatan bahasa Kerinci dibagi menjadi dua bentuk, yakni bentuk sapaan kekerabatan berdasarkan garis keturunan dan berdasarkan garis perkawinan.

\section{Bentuk Sapaan Kekerabatan Berdasarkan Garis Keturunan}




\section{Diagram 1. Kata Sapaan Kekerabatan Berdasarkan Garis Keturunan}

\section{Keterangan}

PY : ibu dari nenek

NK : ibu dari ibu

SPN : saudara perempuan nenek

SLN : saudara laki-laki nenek

IB $\quad:$ ibu

SPI : saudara perempuan ibu

SLI : saudara laki-laki ibu

Pada diagram pohon, dapat dijelaskan bahwa seorang anak yang lahir baik laki-laki maupun perempuan selalu mengikuti garis keturunan dari pihak ibu. Diagram pohon menggambarkan silsilah keluarga yang dimulai dari urutan kelahiran pertama

$\begin{array}{ll}\text { EG } & \text { : penyapa } \\ \text { SP } & \text { : saudara perempuan } \\ \text { SL } & \text { : saudara laki-laki } \\ \text { AN } & \text { : anak } \\ \text { CC } & \text { : cucu } \\ \text { CT } & \text { : cicit }\end{array}$

(PY), kedua (NK, SPN, SLN), ketiga (IB, SPI, SLI), keempat (EG, SP, SL), kelima (AN), keenam (CC), dan ketujuh (CT). Berikut bentuk kata sapaan kekerabatan masyarakat kecamatan Gunung Raya berdasarkan garis keturunan:

\section{Tabel 1. Kata Sapaan Kekerabatan Berdasarkan Garis Keturunan}

\begin{tabular}{lll}
\hline No & Kata Sapaan & Bentuk Sapaan dalam Bahasa Kerinci \\
\hline 1 & Ibu dari nenek & puyai, puye \\
\hline 2 & Ibu dari ibu (nenek) & nino, ninek \\
\hline 3 & Kakak perempuan nenek & nino, ninek \\
\hline 5 & Adik perempuan nenek & nino, ninek \\
\hline 6 & Kakak laki-laki nenek & nanggut \\
\hline 7 & Ibu kandung & nanggut \\
\hline 8 & Kakak perempuan ibu & indok, mak, ama \\
\hline 9 & Adik perempuan ibu & ngah, mak cik, mak dong, mak itam \\
\hline 10 & Kakak laki-laki ibu & itek \\
\hline 11 & Adik laki-laki ibu & mamak, om \\
\hline 12 & Kakak perempuan & mamak, om \\
\hline 13 & Kakak laki-laki & uni, une, kakak, ayuk \\
\hline 14 & Adik perempuan & wo, uda, abang \\
\hline 15 & Adik laki-laki & sebut nama \\
\hline 16 & Anak & sebut nama \\
\hline 17 & Cucu, cicit & sebut nama \\
\hline & & sebut nama, cong \\
\hline
\end{tabular}

Penggunaan kata sapaan puyai dan puye dapat dibedakan antara golongan tua dan golongan muda. Masyarakat yang berusia empat puluh tahun ke atas menggunakan kata sapaan puyai, sedangkan mereka yang berusia di bawah umur empat puluh tahun cendurung menggunakan kata sapaan puye. Kata sapaan nino dan ninek digunakan untuk menyapa ibu dari ibu (nenek), kakak perempuan nenek, dan adik perempuan nenek. Kata sapaan nino merupakan kata asli bahasa Kerinci dialek Gunung Raya, sedangkan 
kata sapaan ninek merupakan kata serapan yang berasal dari bahasa Indonesia. Pada kata ninek terjadi perubahan fonem /e/ menjadi /i/, bentuk asalnya yakni kata nenek.

Kata sapaan nanggut digunakan untuk menyapa kakak maupun adik laki-laki nenek. Kata sapaan indok, mak, ama digunakan untuk menyapa ibu kandung. Kata sapaan indok sudah sangat jarang digunakan oleh masyarakat karena kata sapaan tersebut hanya digunakan oleh masyarakat yang berusia lanjut. Saat ini, kata sapaan yang umum digunakan adalah kata sapaan mak dan ama. Kata sapaan mak merupakan kata serapan dari bahasa Melayu Jambi. Kata sapaan ama berasal dari kata mama, terjadi penghilangan fonem $/ \mathrm{m} /$. Kata sapaan ama sudah menjadi kata sapaan yang umum digunakan oleh generasi muda. Penggunaan kata sapaan ama sudah tidak memandang status sosial karena dipakai oleh semua kalangan masyarakat. Kata sapaan indok tuo dan mak wo digunakan untuk menyapa kakak perempuan ibu yang pertama. Kata sapaan induk ngah dan mak ngah digunakan untuk menyapa kakak perempuan ibu yang kedua ataupun anak tengah.

Kata sapaan yang digunakan untuk menyapa kakak perempuan ibu juga sangat unik karena kata sapaan tersebut tergantung pada ciri fisik seseorang yang disapa. Misal kata mak cik untuk menyapa kakak perempuan ibu yang berbadan kecil, kata mak dong untuk menyapa kakak perempuan ibu yang berbadan gemuk, dan kata mak itam untuk menyapa kakak perempuan ibu yang memiliki kulit berwarna sawo matang. Untuk menyapa adik perempuan ibu, ego menyapanya dengan kata sapaan itek.

Ego menyapa kakak laki-laki dan adik laki-laki ibu menggunakan kata sapaan mamak dan om. Kata sapaan mamak masih digunakan oleh masyarakat yang berumur empat puluh tahun ke atas. Generasi muda mulai terbiasa menggunakan kata sapaan om. Kata sapaan uni, une, kakak, dan ayuk digunakan untuk menyapa kakak perempuan. Kata uni digunakan oleh masyarakat yang berumur empat puluh tahun ke atas. Kata uni berasal dari bahasa Minang. Kata une berasal dari kata uni, terjadi perubahan fonem /i/ menjadi fonem /e/. Kata ayuk berasal dari bahasa Melayu Jambi. Kata kakak berasal dari kata sapaan yang digunakan dalam bahasa Indonesia. Untuk menyapa kakak laki-laki, ego menggunakan kata sapaan wo, $u d a$, dan abang. Kata $u d a$ berasal dari bahasa Minang.

Untuk menyapa adik perempuan, adik laki-laki, dan anak, ego tidak menggunakan kata sapaan tertentu. Saat berkomunikasi, ego dapat menyapa langsung orang yang bersangkutan dengan menyebutkan nama orang tersebut karena usia ego lebih tua dari orang yang disapa. Kata sapaan untuk cicit maupun cucu yakni cong. Masyarakat yang berusia tujuh puluh tahun ke atas menyapa cicit maupun cucunya dengan sebutan cong. Masyarakat yang berusia di bawah tujuh puluh tahun mulai terbiasa dengan menyebut nama cicit maupun cucunya secara langsung.

\section{Bentuk Sapaan Kekerabatan Berdasarkan Garis Perkawinan} perkawinan:

Berikut ini adalah sebuah diagram pohon sapaan kekerabatan berdasarkan garis

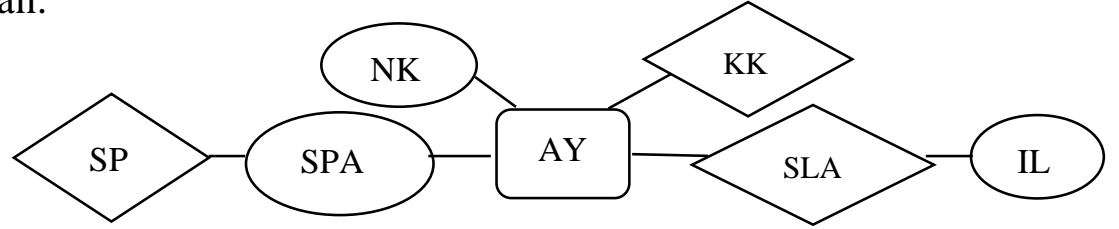

BAHTERA : Jurnal Pendidikan Bahasa dan Sastra, Volume Juli 2021 


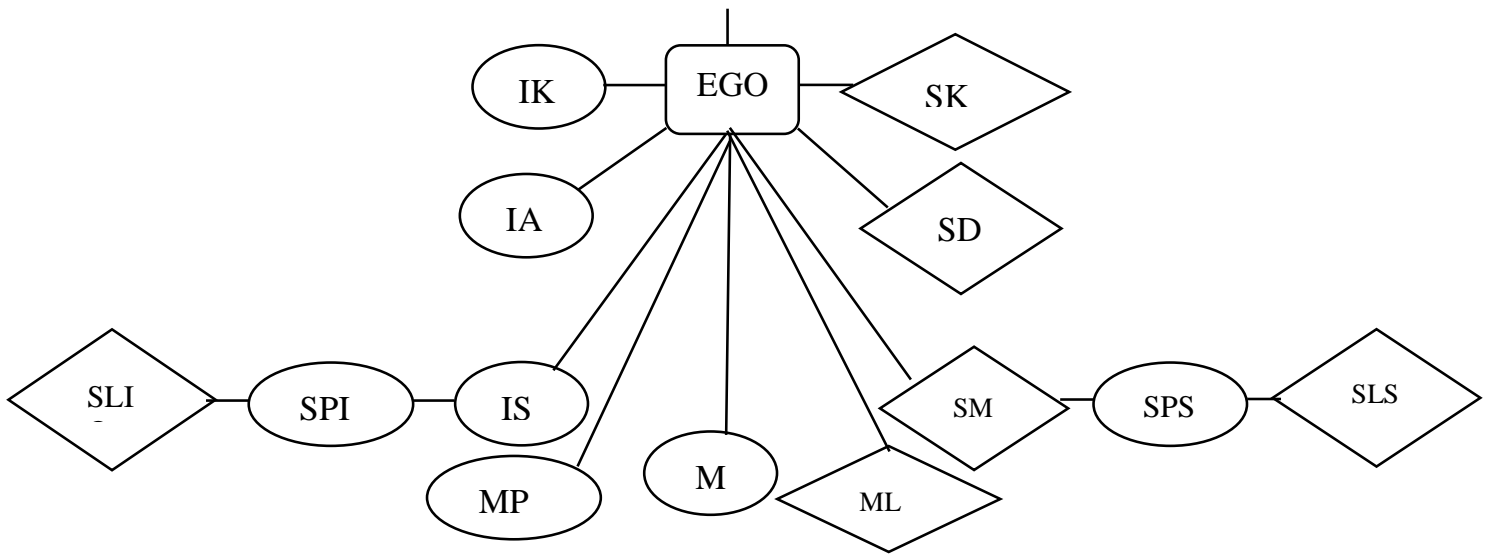

\section{Diagram 2. Kata Sapaan Kekerabatan Berdasarkan Garis Perkawinan}

\section{Keterangan}

NK : ibu dari ayah

KK : ayah dari ayah

AY : ayah

SPA : saudara perempuan ayah

SP : suami saudara perempuan ayah

SLA : saudara laki-laki ayah

IL : istri saudara laki-laki ayah

EGO : penyapa

IK : istri kakak

SK : suami kakak

IA : istri adik

Berdasarkan diagram pohon tersebut, dapat dijelaskan bahwa munculnya hubungan kekerabatan itu karena adanya garis perkawinan. Berikut
SD : suami adik

IS : istri

SLI : saudara laki-laki istri

SPI : saudara perempuan istri

SM : suami

SPS : saudara perempuan suami

SLS : saudara laki-laki suami

MP : mertua perempuan

ML : mertua laki-laki

M : menantu perempuan atau laki-laki

\section{Tabel 2. Kata Sapaan Kekerabatan Berdasarkan Garis Perkawinan}

\begin{tabular}{lll}
\hline No & Kata Sapaan & Bentuk Sapaan dalam Bahasa Kerinci \\
\hline 1 & Ibu dari ayah & nunggoh \\
\hline 2 & Ayah dari ayah & nanggut \\
\hline 3 & Ayah & upok, apa \\
\hline 4 & Saudara perempuan ayah & datung, tante \\
\hline 5 & Suami saudara perempuan ayah & mamak, om \\
\hline 6 & Saudara laki-laki ayah & $\begin{array}{l}\text { pok tuo, pok ngah, pok cik, pok dong, } \\
\text { pok tam, pok tek }\end{array}$ \\
\hline 7 & Istri saudara laki-laki ayah & $\begin{array}{l}\text { Indok tuo, mak wo, indok ngah, mak } \\
\text { ngah, mak cik, mak dong, mak itam, itek }\end{array}$ \\
\hline 8 & Istri kakak & uni, une \\
\hline 9 & Suami kakak & uda, wo \\
\hline 10 & Istri adik & sebut nama, indok..... (nama anaknya) \\
\hline 11 & Suami adik & sebut nama, upok..... (nama anaknya) \\
\hline 12 & Istri & adik, sebut nama \\
\hline
\end{tabular}


E-ISSN : 2540-8968

\begin{tabular}{lll}
\hline 13 & Saudara laki-laki istri & uda, wo \\
\hline 14 & Saudara perempuan istri & uni, une, sebut nama \\
\hline 15 & Suami & uda, wo, sebut nama \\
\hline 16 & Saudara laki-laki suami & uda, wo, sebut nama \\
\hline 17 & Saudara perempuan suami & uni, une, sebut nama \\
\hline 18 & Mertua perempuan & datung, tante \\
\hline 20 & Mertua laki-laki & mamak, om \\
& Menantu perempuan & Sebut nama laki-laki
\end{tabular}

Kata sapaan upok dan apa digunakan untuk menyapa ayah kandung. Penggunaan kedua bentuk sapaan tersebut tergantung pada status sosial ego. Bentuk sapaan apa berasal dari kata papa, terjadi penghilangan fonem /p/. Kata sapaan datung dan tante digunakan untuk menyapa mertua perempuan, kakak perempuan ayah, dan adik perempuan ayah. Masyarakat sering menyingkat kata datung menjadi tung sehingga mereka juga sering menggunakan kata sapaan tung. Kata sapaan tante kebanyakan digunakan oleh kalangan anak muda yang berumur belasan tahun. Kata sapaan mamak dan om digunakan untuk menyapa suami saudara perempuan ayah. Jenis sapaan ini sama dengan sapaan yang digunakan untuk menyapa mertua laki-laki.

Kata sapaan pok tuo, pak wo, pok ngah, pak ngah, pok cik, pok dong, pok itam, dan pok tek digunakan untuk menyapa saudara laki-laki ayah. Kata sapaan tersebut juga digunakan untuk menyapa istri saudara laki-laki ayah. Perbedaan bentuk sapaan tersebut yakni pada kata pok, indok, dan mak pada awal bentuk sapaan. Misalnya, kata sapaan pok tuo untuk menyapa kakak laki-laki ayah, sedangkan kata sapaan indok tuo untuk menyapa istri dari kakak laki-laki ayah. Kata sapaan ditentukan berdasarkan urutan kelahiran. Kata tuo dan wo 'tua' mengacu pada anak tertua. Kata ngah 'tengah' mengacu pada anak kedua atau anak tengah. Sama halnya dengan deskripsi sebelumnya, kata pok cik,mak cik, pok dong, makdong, pok itam dan mak itam mengacu pada ciri fisik tersapa.

Bentuk sapaan uni dan une digunakan untuk menyapa istri kakak, kakak perempuan suami, dan kakak perempuan istri. Pemilihan sapaan uni dan une tergantung pada usia ego. Untuk menyapa istri adik, suami adik, menantu, adik perempuan dan adik lakilaki suami, adik perempuan dan adik laki-laki istri, ego memanggil namanya secara langsung atau memanggilnya dengan sapaaan indok... (nama anaknya) dan sapaan upok... (nama anaknya). Berikut contohnya dalam tuturan:

A: mano ngok isok, pok Nuri? mbuh nolong datung mukut kawa

'mau kemana besok bapaknya Nuri? bisakah membantu tante panen kopi?'

B: lom ado rencana nak kamano, jadi go tung

'belum ada rencana kemanamana, bisa tante'

Pada konteks percakapan di atas, mertua memanggil menantunya dengan bentuk sapaan kata + nama anak.

Kata sapaan $u d a$ dan wo digunakan untuk menyapa suami kakak, saudara laki-laki istri, dan suami. Pemilihan bentuk sapaan yang akan digunakan tergantung pada ego, namun ada juga ego yang menyapa suaminya dengan menyebutkan nama suaminya secara langsung. Bentuk sapaan adik digunakan untuk menyapa istri. Di 
samping itu, ada ego yang menyapa istrinya dengan menyebut nama orang yang bersangkutan secara langsung.

Faktor Sosial yang Mempengaruhi Variasi Kata Sapaan Kekerabatan Bahasa Kerinci di Kecamatan Gunung Raya

Ada beberapa faktor yang mempengaruhi sistem sapaan kekerabatan dalam bahasa Kerinci di desa kecamatan Gunung Raya, yaitu:

Jarak Sosial

Dalam sistem sapaan

kekerabatan bahasa Kerinci di kecamatan Gunung Raya, ego memiliki hubungan yang dekat dengan tersapa karena garis keturunan dan garis perkawinan. Ego harus memperhatikan identitas tersapa. Misalnya, ego memperhatikan kedudukan tersapa dalam silsilah keluarga, apakah tersapa merupakan paman, bibi, kakek, nenek, dan lainnya. Jika ego berusia lebih tua dari orang yang disapa maka tidak ada kata sapaan tertentu yang digunakan. Ego dapat menyapa orang yang lebih muda darinya dengan menyebut nama orang yang bersangkutan.

Usia

Kata sapaan kekerabatan dalam bahasa Kerinci di kecamatan dipengaruhi oleh faktor usia. Jika ego lebih muda dari tersapa, ego harus menggunakan kata sapaan tertentu seperti mak, pok tuo, itek, dan lainnya. Jika ego lebih tua dari tersapa, ego bisa langsung menyebutkan nama tersapa. Faktor usia juga berpengaruh pada jenis kata sapaan yang dipilih, apakah kata sapaan tersebut merupakan bentuk sapaan asli bahasa Kerinci atau bentuk sapaan dari bahasa daerah lain. Masyarakat yang berusia lanjut justru masih menggunakan sapaan asli bahasa Kerinci di Kecamatan Gunung Raya, sedangkan masyarakat yang berusia muda cenderung menggunakan istilah sapaan baru yang terus mengalami penambahan dan perkembangan. Setiap ada istilah baru yang muncul, masyarakat desa Lempur Mudik cenderung menerima dan mengikutinya.

\section{Jenis Kelamin}

Jika jenis kelamin tersapa berbeda, bentuk sapaannya juga berbeda. Misalnya, bentuk sapaan yang digunakan untuk menyapa ayah dari ayah (kakek) adalah "nanggut" dan sapaan yang digunakan untuk menyapa ibu dari ayah (nenek) adalah "nunggoh".

Status Sosial

Status sosial masyarakat berpengaruh terhadap bentuk kata sapaan yang dipilih. Masyarakat yang berprofesi sebagai pegawai swasta maupun pegawai negeri sipil cenderung menggunakan kata sapaan yang muncul akibat adanya kontak bahasa dalam masyarakat multilingual, sedangkan masyarakat yang berprofesi sebagai petani masih menggunakan kata sapaan asli bahasa Kerinci di kecamatan Gunung Raya.

\section{Ciri- ciri Fisik}

Adanya variasi kata sapaan bahasa Kerinci di kecamatan Gunung Raya juga disebabkan karena ego memperhatikan ciri-ciri fisik orang yang disapa. Adapun ciri-ciri fisik yang dimaksud yakni postur tubuh dan warna kulit. Misalnya orang yang tersapa memiliki postur tubuh kecil, ego menyapa orang tersebut dengan sapaan makcik. Kata makcik berasal dari kata mak dan cik. Kata cik mengacu pada postur tubuh yang kecil karena kata $c i k$ bermakna kecil.

\section{Kontak Bahasa}

Masyarakat kecamatan Gunung Raya dapat disebut sebagai masyarakat yang bilingual karena mereka menguasai lebih dari satu bahasa. Kecamatan Gunung Raya juga dihuni oleh orang-orang dari beragam etnis 
seperti etnis Kerinci, Jawa, Minang, dan Melayu. Kontak bahasa dapat terjadi dalam masyarakat yang multilingual dan multietnis. Dalam suatu masyarakat, kontak bahasa terjadi antara bahasa ibu dan bahasa dari etnis lainnya (Mutmainnah dkk, 2018). Dampak kontak bahasa yang terjadi di Kerinci yakni adanya peminjaman kata dari bahasa lain. Ada beberapa bentuk kata sapaan kekerabatan bahasa Kerinci di kecamatan Gunung Raya yang berasal dari bahasa Minang dan bahasa Melayu Jambi. Misalnya, kata sapaan $u d a$ dan uni berasal dari bahasa Minang.

\section{KESIMPULAN DAN SARAN}

Berdasarkan data yang telah dikumpulkan, dapat disimpulkan bahwa menurut adat kecamatan Gunung Raya, sistem kekerabatan masyarakat kecamatan Gunung Raya menarik garis keturunan matrilineal, artinya seorang yang dilahirkan mengikuti garis keturunan pihak perempuan. Pihak lakilaki menjadi kerabat berdasarkan garis perkawinan. Kata sapaan kekerabatan bahasa Kerinci di Kecamatan Gunung Raya berdasarkan garis keturunan terdiri atas 25 kata sapaan, sedangkan kata sapaan kekerabatan bahasa Kerinci di kecamatan Gunung Raya berdasarkan garis perkawinan terdiri atas 29 kata sapaan. Faktor-faktor sosial yang mempengaruhi bentuk-bentuk kata sapaan kekerabatan bahasa Kerinci di kecamatang Gunung Raya yakni jarak sosial, usia, jenis kelamin, status sosial, ciri-ciri fisik, dan kontak bahasa.

Sebagai warna negara Indonesia yang baik, masyarakat diharapkan dapat menguasai dan menggunakan bahasa daerah dalam kehidupan sehari-hari. Sikap positif yang ditunjukkan terhadap bahasa daerah dapat mencegah punahnya bahasa-bahasa daerah di Indonesia. Salah satu contoh sikap positif terhadap bahasa daerah, yakni penutur terus menggunakan kata sapaan kekerabatan dalam berkomunikasi sehari-hari.

\section{DAFTAR PUSTAKA}

Barlian, E. (2016). Metodologi Penelitian Kualitatif \& Kuantitatif. Padang: Sukabina Press.

Chaer, A dan Agustina, L. (2010). Sosiolinguistik Perkenalan Awal. Jakarta: Rineka Cipta.

Dama, D. (2018). "Greeting Variety to Show Politeness in Gorontalo Language". BAHTERA: Jurnal Pendidikan Bahasa dan Sastra, 17(2), 24-33.

https://doi.org/https://doi.org/10.21 009/BAHTERA.172.03

Habsi, R. (2018). "Penggunaan Sapaan Kekerabatan Bahasa Makean Dialek Samsuma di Desa Samsuma Kecamatan Malifut". Jurnal Kajian Linguistik, 6(1), 5265.

https://ejournal.unsrat.ac.id/index.p hp/kaling/article/view/24782

Hildayani, D. (2019). "Cross-Cultural Communication: Javanese and Sundanese Vocabularies the Same in Form and Different in Meaning". BAHTERA: Jurnal Pendidikan Bahasa dan Sastra, 18(2), 176-185.

https://doi.org/10.21009/bahtera.18 2.07

Jannah, M., Bahry, R., \& Mahmud, S. (2019). "Penggunaan Sapaan Kekerabatan dalam Tuturan Masyarakat Kabupaten Batu Bara Provinsi Sumatra Utara". Jurnal Bahasa dan Sastra, 13(2), 143158.

http://jurnal.unsyiah.ac.id/JLB/arti cle/view/14768

Maiza, S. (2018). "Sistem Perulangan Bahasa Kerinci Dialek Rawang". Jurnal Menara Ilmu, 12(79), 213220. 
https://jurnal.umsb.ac.id/index.php /menarailmu/article/view/556/495

Masruddin. (2015). Sosioliguistik. Sulawesi Selatan: Read Institute Press.

Mawara, J. E. T. (2015). "Solidaritas Kekerabatan Suku Bangsa Bantik Di Kelurahan Malalayang I Manado". Jurnal Acta Diurna, 4(2), 1-13.

https://ejournal.unsrat.ac.id/index.p hp/actadiurna/article/view/7254

Misnawati. (2017). "Kata Sapaan Bahasa Minangkabau: Penggunaan dan Kategorisasi". Jurnal Elektronik Wacana Etnik, 8(1), 13-20.

http://wacanaetnik.fib.unand.ac.id/ index.php/wacanaetnik/article/vie $w / 65$

Rina, N., \& Rahman, F. (2016). "Analisis Absolute dan Oblique dalam Bahasa Kerinci Isolek Pulau Tengah". Jurnal Artbitrer, 3(2), 152-165.

http://arbitrer.fib.unand.ac.id/index .php/arbitrer/article/view/48/38

Suhardi, B. (2017). Pedoman Penelitian Sosiolinguistik. Jakarta: Pusat Bahasa.

Suwija, I. I. (2018). "Sistem Sapaan Bahasa Bali Menurut Hubungan Kekerabatan". Jurnal Sosiohumaniora: Jurnal Ilmu-ilmu Sosial dan Humaniora, 20(2), 115-121.

https://doi.org/10.24198/sosiohum aniora.v20i2.16731

Temaja, I. G. B. W. B. (2018). "Sapaan Kekerabatan Dalam Bahasa Bali (Kinship Addresses in Balinese Language". Jurnal Metalingua 16(2), 211-220.

Yudi Aditama, V dkk (2020). "Pengunaan Sapaan Bahasa Kerinci Dialek Jujun". Basindo: Jurnal Kajian Bahasa, Sastra Indonesia, dan Pembelajarannya,
4(1), 135-143.

http://journal2.um.ac.id/index.php/ basindo/article/view/14745/5985

Wardhaugh, R., \& Fuller, J. M. (2015). An Introduction to Sociolinguistics. UK: Willey Blackwell. 